\title{
CRENÇAS DE ALUNOS BRASILEIROS (DE JAPONÊS COMO LE) EM RELAÇÃO À HABILIDADE DE FALA EM LIINGUA JAPONESA ${ }^{1}$
}

Flávia R. Feijón

Yûki Mukai ${ }^{3}$

Resumo: Apesar das pesquisas de crenças sobre aprendizagem de línguas terem crescido significativamente, trabalhos mais específicos e que abrangem diversas línguas ainda são escassos (BARCELOS, 2003b, 2006, 2007). Sendo assim, a presente pesquisa investigou as crenças de alunos brasileiros de língua japonesa como língua japonesa (LE) em relação à sua habilidade de fala na língua-alvo. A metodologia de investigação utilizada foi a pesquisa qualitativa e sua natureza foi um estudo de caso. O contexto analisado foi uma universidade pública do Distrito Federal e os participantes foram dois alunos não nikkei (não descendentes de japoneses). Foram analisadas as relações entre as crenças, ações e as escolhas das estratégias de aprendizagem dos alunos, bem como a origem das crenças baseadas nas suas experiências anteriores de aprendizagem. Os resultados mostraram que as crenças dos participantes influenciam no uso e desenvolvimento de suas habilidades de fala e estão diretamente ligadas às expectativas de sucesso e fracasso no uso do japonês pelos alunos.

Palavras-chave: Crenças; Habilidade de fala; Estratégias de aprendizagem, Ações; Experiências anteriores de aprendizagem.

1 Esta foi uma pesquisa realizada no ano 2010 como trabalho de conclusão de curso da aluna Flávia Rocha Feijó, com orientação do professor doutor Yuki Mukai. Os resultados da pesquisa foram apresentados VIII Congresso Internacional de Estudos Japoneses no Brasil, XXI Encontro Nacional de Professores Universitário de Língua, Literatura e Cultura Japonesa, Universidade de Brasília, UnB, Brasília, 2010.

2 Flávia Rocha Feijó é mestranda do Departamento de Linguagem e Ciência da Informação da Universidade de Tokyo, Tóquio, Japão; flavia.rfeijo@gmail.com

3 Yûki Mukai é Professor Adjunto do Departamento de Línguas Estrangeiras e Tradução (LET) da Universidade de Brasília (UNB), Brasília, Brasil; yuki@unb.br 
Abstract: Although researches on beliefs about language learning has grown significantly in number, the number of the studies that cover different languages and different topic/subareas is still scare (BARCELOS, 2003b, 2006, 2007). Hence, the purpose of the present study was to elucidate the Brazilian students' beliefs about their speaking ability in the target language. The research methodology was qualitative, using a comparative case study design. The analyzed context was a public university of the Federal District, and the participants were two students of non-Japanese descent. The relationships between the beliefs, participants' actions and the use/choice of learning strategies were analyzed. The origins of beliefs based on students' previous learning experiences were also investigated. The results showed that the students' beliefs influence the use and development of their speaking ability and the participants' expectation of success or failure are also directly related to the use of Japanese language.

Keywords: Beliefs; Speaking ability; Learning Strategies; Actions; Previous learning experiences.

\section{INTRODUÇÃO}

Woods (2003) afirma que a noção de crenças de aprendizes e professores e os papeis que elas exercem no processo de aprendizagem de línguas vêm sendo tratados de maneira periférica dentro da literatura de aquisição de segunda língua. Barcelos $(2003 b, 2006)$ ressalta que o conceito de crenças é um tópico de investigação dentro da Linguística Aplicada (doravante LA) há quase duas décadas e que o interesse de pesquisas na área de crenças vem crescendo consideravelmente desde os últimos anos.

Os estudos sobre investigação de crenças, tanto no contexto internacional quanto no nacional, sobre aprendizagem de línguas são divididos por Barcelos (2003b, 2004) de acordo com três abordagens distintas: a abordagem normativa, cognitiva e contextual. Os estudos agrupados dentro da abordagem normativa compreendem que as crenças são conceitos preconcebidos e que influenciam na abordagem de aprender dos alunos (cf. BARCELOS, 2001, p. 76-77; BARCELOS, 2003b, p. 11; VIERA ABRAHÃO, 2005, p. 219). Os estudos agrupados dentro da abordagem cognitiva conceituam crenças como sendo um conhecimento metacognitivo (cf. BARCELOS, 2001, p. 79; BARCELOS, 2003b, p. 16; VIEIRA ABRAHÃO, 2005, p. 219;). Este se refere à "informação que os alunos adquirem sobre suas aprendizagens" ${ }^{4}$ (WENDEN, 1999, p. 436). A abordagem contextual engloba estudos, que se preocupam, pela primeira vez, com o contexto de aprendizagem e as crenças são investigadas por meio de "observações de sala de aula e análise do contexto" (BARCELOS, 2001, p. 81).

Ressaltamos que durante mais de 15 anos de estudos sobre crenças de ensino e aprendizagem de línguas, o número de trabalhos produzidos, publicados

4 Tradução nossa. No original: “ information learners acquire about their learning”. 
e apresentados a respeito do tema em foco tem crescido consideravelmente (cf. BARCELOS, 2003b, 2006). Todavia, a pesquisa em crenças ainda carece de trabalhos mais específicos (crenças sobre a oralidade, escrita, leitura de texto, entre outros) que enfoquem outras línguas estrangeiras além da língua inglesa (cf. BARCELOS 2006, 2007). Barcelos (2003b) ainda ressalta que, apesar da existência de alguns estudos que levem em consideração o contexto, "nós ainda sabemos muito pouco sobre as funções das crenças na cultura da sala de aula" ${ }^{5}$ (op.cit., p. 27). O número de trabalhos publicados sobre crenças de professores e alunos em relação à língua japonesa também é ainda escasso (cf. FEIJO; MUKAI, 2012; MUKAI, 2011a, 2011b; MUKAI; CONCEIÇÃO, 2012). Dentro desta perspectiva, realizamos a presente pesquisa com intuito de contribuir para a literatura de crenças tanto no contexto nacional como internacional, bem como, para o fortalecimento da área de estudos sobre crenças.

\section{O ESTUDO}

A presente pesquisa teve início com questionamentos de alunos do $5^{\circ}$ semestre do ano de 2010 de um curso de Língua e Literatura Japonesa de uma universidade pública do Distrito Federal a respeito de sua habilidade de fala em língua japonesa. Percebeu-se por meio de conversas informais que estes alunos sentiam-se inseguros e incapazes de comunicar-se na língua-alvo ${ }^{6}$. Com intuito de identificar quais os problemas e as dificuldades enfrentados por estes no uso de sua habilidade de fala no idioma japonês, foram propostos os seguintes objetivos de pesquisa:

1. Identificar as crenças destes alunos em relação à habilidade de fala na língua japonesa;

2. Identificar a origem destas crenças baseada nas experiências anteriores de aprendizagem dos alunos;

3. Verificar como estas crenças influenciam as ações de aprendizagem dos alunos;

5 Tradução nossa. No original: "we still know very little about the functions of beliefs in the culture of the classroom".

6 A definição para língua-alvo que utilizamos na presente pesquisa é a mesma apresentada no trabalho de Mukai (2009, p. 10), onde a língua-alvo refere-se à "língua japonesa padrão", baseada no dialeto de Tóquio. O motivo de incorporamos essa definição na nossa pesquisa, pois a língua ensinada na Universidade Pública do Distrito Federal, no curso de Letras-Japonês, contexto da presente pesquisa, é baseada no dialeto de Tóquio. 
4. Verificar como estas crenças influenciam na escolha de suas estratégias de aprendizagem da parte oral do japonês;

5. Verificar como as ações destes alunos influenciam suas crenças;

6. Verificar como as estratégias de aprendizagem utilizadas por estes alunos influenciam suas crenças.

\section{DEFINIÇÃO DOS CONCEITOS-CHAVE}

\subsection{Crenças}

Definir o termo crenças não é uma tarefa fácil, visto que o seu conceito não é único da LA (cf. BARCELOS, 2000, 2003b, 2007). Pajares (1992, p.309) também ressalta sobre a dificuldade de se definir este conceito global, ressaltando a existência de uma variedade de terminações utilizadas para definir crenças. Dentro da própria LA diferentes termos foram usados para referirem-se a crenças, tais como, "cultura de aprender" (BARCELOS, 1995) e "conhecimento metacognitivo" (WENDEN, 1999).

Horwitz (1987, p. 119-120) define crenças como uma ideia pré-existente, que podem ser influenciadas pelas experiências anteriores de aprendizagem de línguas e culturas dos aprendizes. Wenden $(1987,1999)$ refere-se ao termo crenças de aprendizes como termo sinônimo de conhecimento metacognitivo, onde as crenças dos alunos são suas "teorias em ação" (WENDEN, 1987, p. 112). Kramsch (2003a) afirma que as "crenças são reflexos de uma realidade psíquica estável dentro da mente de professores e alunos"" (op. cit., p. 125). Kalaja (1995, p. 196) sugere uma reconsideração sobre o termo crenças, definindo-o como algo "socialmente construído, emergindo das interações sociais com outros"10, ou seja, as crenças não passam a ser vistas somente como um conhecimento cognitivo, mas socialmente construídas, interativas, sociais e variáveis.

Os estudos de Barcelos (2000, 2003a) e Conceição (2004) sugerem que a filosofia de Dewey é ideal para a compreensão de crenças sobre aprendizagem de línguas, pois ressalta que estas são "contextuais e baseadas nas nossas experiên-

7 Tradução nossa. No original: "metacognitive knowledge".

8 Tradução nossa. No original: "theories-in-action".

9 Tradução nossa. No original: "beliefs are reflections of a stable psychic reality in the mind of teachers and learners".

10 Tradução nossa. No original: "socially constructed, emerging from interaction with others". 
cias" (BARCELOS, 2003a, p. 173). No presente trabalho também tomamos como base referencial teórica a definição do terceiro sentido de pensamento de Dewey (1933), de pensar como sinônimo de crer, para definir que crenças:

abrangem todos os assuntos que não temos conhecimento seguro, mas em que confiamos o bastante para nelas basear nossa ação; e, igualmente, os assuntos que temos como verdadeiros, suscetíveis, todavia, de futuros questionamentos. (DEWEY, 1933, p. 6) (Tradução nossa) ${ }^{11}$.

Segundo Dewey (op. cit.) as crenças não são providas de valores de julgamento de certo e errado, mas que fazem a afirmação sobre algum fato, princípio ou lei. Ressaltamos que no presente estudo também concordamos com a visão de Barcelos (2006) e Kalaja (1995) de que as crenças não são processos apenas cognitivos, mas sim sociais e contextuais, onde as crenças são passíveis de uma constante ressignificação e possuem sua origem nas experiências de aprendizagem e ensino dos alunos e professores (BARCELOS, 2001, 2006, 2007).

\subsection{A relação entre crenças e ações}

Wood (2003) ressalta que a relação entre crenças e ações é um tópico "central para a investigação sobre crença de aprendizes"12 (op. cit., p. 208). Segundo Horwitz (1999) "as crenças de aprendizes possuem um potencial de influenciar tanto suas experiências como suas ações como aprendizes de línguas"13 (HORWITZ, op. cit., p. 558). Pajares (1992, p. 317) também discorreu sobre a relação entre crenças e ações afirmando que "as crenças influenciam as percepções, que influenciam o comportamento ${ }^{14}{ }^{15}$. Woods (2003, p. 206 e 208) afirma que existe uma relação entre as ações que os aprendizes e suas crenças, e que esta, por sua vez influencia outras ações, decisões, eventos e a interpretação destes.

Alguns estudos recentes como Barcelos (2000, 2001, 2003a, 2006) enfatizam como as crenças influenciam as ações, e estas, por sua vez, podem influenciar na

11 No original: "It covers all the matters of which we have no sure knowledge and yet which we are sufficiently confident of to act upon and also the matters that we now accept as certainly truer, as knowledge, but which nevertheless may be questioned in the future".

12 Tradução nossa. No original: "the relationship between beliefs and action is central to research on learner beliefs".

13 Tradução nossa. No original: "Learners beliefs have the potential to influence both their experience and actions as language learners".

14 No presente trabalho não discutimos a diferença entre comportamento, ações e desempenho, sendo estas usadas como sinônimos.

15 Tradução nossa. No original: "Beliefs influence perceptions that influence behavior ". 
concepção ou ressignificação das crenças. Hosenfeld (2003, p. 37) em seu estudo afirma que "existe uma forte ligação entre as crenças emergentes e os comportamentos de aprendizagem (ações)"16 (parênteses nossos). Tanaka e Ellis (2003, p. 63) ressaltam que as crenças influenciam no comportamento dos alunos e nos seus estados afetivos, como confiança e ansiedade. A filosofia de Dewey (1933) refere-se à ação como um ato ligado ao pensamento.

\subsection{A relação entre crenças, contexto e a experiência anterior de aprendizagem}

Dewey (1933) afirma que por as crenças envolverem algum tipo de comprometimento emocional, prático e intelectual, necessitarão mais cedo ou mais tarde, de uma investigação para descobrir suas bases, e por consequência, suas origens. Barcelos (2004) afirma que

(as) crenças não são somente um conceito cognitivo, mas também social porque nascem das nossas experiências e problemas, de nossa interação com o contexto e da nossa capacidade de refletir e pensar sobre o que nos cerca. (op. cit., p. 132).

Conceição (2004) ressalta a importância da investigação de experiências anteriores, ou histórias de aprendizagem, pois estas podem explicar muitas das dificuldades e ações dos aprendizes durante seu processo de aprendizagem. Woods (2003) afirma que as crenças são contextuais, pois elas não são "entidades estáveis dentro do indivíduo, mas situadas nos contextos sociais e formadas em instâncias específicas de interação social, e como resultado, estão constantemente envolvendo"17 (op. cit., p. 202). Os estudos de Kramsch (2003) e Tanaka e Ellis (2003) também mostram que as crenças e as suas concepções envolvem o contexto social e as experiências pessoais anteriores.

\subsection{As crenças e as estratégias de aprendizagem}

Conceição (2004) ressalta que o papel do professor como "grande promotor de aprendizagem" tem sido substituído para a "consciência da importância da responsabilidade do aluno em frente à sua aprendizagem" (op. cit., p. 41). Em outras palavras, os aprendizes passaram a possuir um papel ativo no seu

16 A autora difere os termos crenças estáveis, que os alunos "possuem em suas mentes e trazem durante a aprendizagem", e crenças emergentes, "que surgem durante a aprendizagem” (HOSENFELD, 2003, p. 39).

17 Tradução nossa. No original: "Beliefs are not stable entities within the individual, but situated in social context and formed through specific instances of social interaction and, as a result, are constantly evolving". 
processo de aprendizagem. Barcelos (2004) também ressalta que o foco de estudo da LA também está no aprendiz, visto como sujeito ativo no processo de aprendizagem. Desta maneira, é importante que estes aprendizes reflitam sobre o seu processo de aprendizagem e as suas estratégias de aprendizagem a fim de obterem êxito em seus estudos. Mukai (2009, p. 63) afirma que para que o processo de ensino-aprendizagem de LE/L2 seja bem-sucedido, são precisos além da didática dos professores, o reconhecimento e a consciência por parte de seus alunos a respeito de suas estratégias de aprendizagem. Segundo Horwitz (1987), o propósito de se investigar as estratégias de aprendizagem dos alunos é uma tentativa "de determinar quais estratégias são mais efetivas e ajudar os aprendizes a escolherem os procedimentos mais efetivos de aprendizagem" 18 (op. cit., p. 126).

A noção de estratégias de aprendizagem (doravante EA) está relacionada com "ações específicas do aprendiz para tornar a aprendizagem mais fácil, rápida, agradável, centrada, efetiva e transferível para novas situações"19 (OXFORD, 1990, p. 8). Como citado na seção anterior, as crenças exercem influência sobre as ações dos aprendizes (cf. BARCELOS, 2000, 2001, 2003a, 2006; PAJARES, 1992; TANAKA; ELLIS, 2003; WENDEM, 1987; WOODS, 2003), e estas por sua vez, também influenciam na escolha e uso das EA pelos alunos no processo de aprendizagem de uma língua estrangeira. Horwitz (1987, p. 120) afirma que "as crenças de aprendizes sobre aprendizagem de línguas podem influenciar suas estratégias de aprendizagem" 20 . Wenden (1987) investigou as crenças de aprendizes sobre a melhor abordagem de se aprender uma segunda língua, incluindo suas EA. O estudo de Abraham e Vann (1987) mostrou conexões entre as crenças e as escolhas das estratégias de aprendizagem de estudantes de inglês. No Brasil, Conceição (2004) investigou a relação entre crenças e as EA no contexto de aprendizagem de língua inglesa como LE com foco nas estratégias do uso de dicionário em sala de aula. A autora também afirma que a sala de aula pode ser compreendida como um palco onde os aspectos socioculturais, experiências, valores, crenças e as práticas de aprendizagem são compartilhados e contribuem para escolha e uso de EA específicas.

18 Tradução nossa. No original: “... to determine which strategies are most effective and help students adopt more productive learning procedures”.

19 Tradução nossa. No original: "learning strategies are specific actions taken by the learner to make learning easier, faster, more enjoyable, more self-directed, more effective, and more transferable to new situations".

20 Tradução nossa. No original: "Students beliefs about language learning can influence their language learning strategies". 


\section{O CONCEITO DE HABILIDADE DE FALA}

A aprendizagem e o uso apropriado de uma nova língua envolvem o desenvolvimento de quatro habilidades, sendo elas a fala, a leitura, a compreensão oral e a escrita (KAWAGUCHI; YOKOMIZU, 2005; KONDOH; KOMORI, 2012). Estas são chamadas "quatro habilidades linguísticas" ou "quatro habilidades" (OXFORD, 1990, p. 6). Horowitz e Berkowitz (1967) afirmam que a audição e a leitura são processos de "aquisição" e a fala e a escrita são processos de "reprodução" (op. cit., p. 207). Ou seja, a fala e a escrita "são simplesmente canais aonde o pensamento é expressado" ${ }^{21}$ (HOROWITZ; BERKOWITZ, op. cit., p. 209). Dean e Bryson (1961) ressaltam que ambas as habilidades de fala e escrita exigem "um comando adequado da língua" 22 (op. cit., p. 10). A habilidade da fala (doravante HF), ao contrário da escrita, manifesta-se na presença de um interlocutor ou audiência, onde o falante utiliza-se da fala para expressar suas ideias e pensamentos. (cf. DEAN; BRYSON, 1961).

Kondoh e Komori (2012) afirmam que a fim de estabelecer uma comunicação é necessário que a "intenção do enunciado" ${ }^{23}$ seja expressa por meio da fala e que haja escolha de um discurso apropriado, levando em consideração o seu interlocutor. Este discurso apropriado refere-se ao uso da HF, que envolve a escolha apropriada de vocabulário, expressões e estruturas gramaticais e a sua real produção para um interlocutor por meio do ato de fala. Compreendemos que um ato de fala envolve três processos interligados: o primeiro seria o pensamento do conteúdo a ser dito, o segundo a escolha das expressões a serem utilizadas e o terceiro o ato real de fala dirigida a um interlocutor específico (FUNDAÇAO JAPAO, 2007).

Portanto, a HF é uma das competências necessárias para a comunicação (OXFORD, 1990, p.7), onde alunos expressam suas ideias e pensamentos para seu interlocutor ou audiência num determinado contexto por meio da escolha adequada de vocabulário, expressões e formas gramaticais.

\section{METODOLOGIA}

A metodologia de investigação utilizada é a pesquisa qualitativa, que pode ser definida como "um meio de explorar e entender indivíduos e grupos a respeito de um problema social ou humano" ${ }^{24}$ (CRESWELL, 2009, p. 4). O foco de

21 Tradução nossa. No original: "[...] are simply the channels through which thought is expressed".

22 Tradução nossa. No original: "[...] require an adequate command of language".

23 Tradução nossa. No original: “発話意図” (op. cit., pg. 245)

24 Tradução nossa. No original: "Qualitative research is a means for exploring and understanding the meaning individuals or groups ascribe to a social or human problem". 
investigação de uma pesquisa qualitativa está nos "cenários naturais" (DENZIN; LINCOLN, 2006, p. 17), onde o pesquisador busca compreender os fenômenos situados socialmente e com foco na qualidade dos processos analisados. A abordagem utilizada é a contextual, que procura investigar as crenças em conjunto com as ações dos alunos e as descreve "embutidas" no contexto dos alunos (BARCELOS, 2003b, p. 19). A sua natureza é um estudo de caso, que é definido como um "estudo de uma unidade de análise", cujo foco está centrado numa "única unidade, cuja existência está ocorrendo naturalmente no meio ambiente" (JOHNSON, 1992, p. 75). A escolha desta natureza é devido à sua característica que propõe a "descrição e explicação de um fenômeno único isolado e pertencente a um determinado grupo ou classe" (TELLES, 2002, p. 108). Portanto, a presente pesquisa não possui como objetivo generalizar as crenças de aprendizes em relação à sua habilidade de fala, mas sim investigar as crenças de aprendizes inseridos em um contexto universitário específico.

\subsection{Contexto}

A pesquisa foi realizada no primeiro semestre letivo do ano de 2010 de uma universidade pública do Distrito Federal no curso de Licenciatura em Língua e Literatura Japonesa, nas aulas de Japonês Expressão Oral 1 e 2 (doravante JEO1 e JEO2). O curso de japonês é dividido em dois níveis, o básico e o intermediário. As aulas de JEO1 e JEO2 são disciplinas optativas ministradas para os alunos do $5^{\circ}$ ao $8^{\circ}$ semestre, correspondente ao nível intermediário.

\subsection{Participantes da pesquisa}

Devido à nossa pesquisa ser um estudo de caso e estar baseada na abordagem contextual, delimitamos o número de participantes a um número reduzido. Barcelos (2001, p.82) afirma que estudos dentro da abordagem contextual são conduzidos com um número reduzido de participantes devido a uma grande demanda de tempo e dedicação por parte dos pesquisadores e participantes.

Os participantes foram alunos brasileiros não nikkei, sem descendência japonesa, das turmas de JEO1 e JEO2, sendo um participante de cada turma. Nina (nome fictício), sexo feminino, 19 anos, estava no $5^{\circ}$ semestre do curso de japonês e cursava a disciplina de JEO1. O informante Pedro (nome fictício), sexo masculino, 24 anos, estava no $6^{\circ}$ semestre e cursava a disciplina de JEO2.

Ressaltamos que na turma de JEO1 havia 9 alunos, sendo 2 alunos nikkei e 7 alunos não nikkei, e na turma de JEO2 havia 5 alunos, sendo 3 alunos nikkei e 2 não nikkei. A delimitação da pesquisa para alunos brasileiros não nikkei ocorreu 
pelo fato destes alunos terem aprendido a língua japonesa como LE e não como segunda língua (L2). Apesar de haver mais de um aluno não nikkei nas turmas de JEO1 e JEO2, os alunos foram escolhidos de acordo com a disponibilidade e o interesse pessoal em participar da pesquisa.

\subsection{Aulas de JEO1 e JEO2}

Conforme mencionado anteriormente as aulas de JEO1 e JEO2 são ministradas uma vez por semana. Cada aula possui duração de uma hora e quarenta minutos e são disciplinas optativas do currículo do curso superior de língua japonesa. No primeiro semestre de 2010, as aulas de JEO1 ocorriam todas as quintas-feiras, das 20 horas e 50 minutos às 22 horas e 30 minutos. A aula era ministrada por um professor nativo da língua japonesa. $\mathrm{O}$ idioma mais utilizado em sala de aula era o japonês. O português era somente usado quando os alunos não conseguiam compreender alguma estrutura utilizada pelo professor ou quando não sabiam algum vocabulário na língua-alvo durante os exercícios orais de diálogos. As aulas de JEO2 também ocorreriam todas as quintas-feiras, das 19 horas às 20 horas e 40 minutos. A mesma era ministrada por um professor falante nativo do português. $\mathrm{O}$ idioma mais utilizado era o português e o japonês era somente utilizado nas interações entre alunos durante debates e exercícios orais de fala.

\subsection{Instrumentos de coleta}

Segundo Seliger e Shohamy (1989, p. 122) “diversos instrumentos de coleta de dados são usados no mesmo estudo com intuito de copilar uma figura mais completa do objeto ou evento investigado" 25 . Neste sentido, com o intuito de conferir uma maior veracidade aos resultados apresentados na presente pesquisa, foram utilizados os seguintes instrumentos de coleta de dados: questionário semiaberto (Q1) (vide apêndice A), entrevistas semiestruturadas com gravação de áudio (E1), questionário fechado (BALLI ${ }^{26}$ adaptado) (Q2) (vide apêndice B), narrativas por escrito sobre a história de aprendizagem da parte oral do japonês (N1), observações de aula com notas de campo.

25 Tradução nossa. No original: "[...] several different methods are used in the same study in order to compile a more complete picture of the activity or event being described".

26 Beliefs About Language Learning Inventory (Inventário de crenças sobre aprendizagem de línguas) (HORWITZ, 1987). 


\subsection{Procedimento de análise dos dados}

Os dados coletados durante o primeiro semestre de 2010 foram submetidos a uma análise qualitativa com a triangulação dos dados com a finalidade de identificar os mesmos padrões por meio de diferentes instrumentos (SELIGER; SHOHAMY, op. cit., p. 123; JOHNSON, 1992, p. 90). Ou seja, os dados coletados foram organizados e preparados em categorias, analisados e interpretados (CRESWELL, 2009) com o intuito de identificar as crenças de Nina e Pedro em relação à sua habilidade de fala, a origem dessas crenças e como estas crenças influenciam e são influenciadas pelas ações e estratégias de aprendizagem dos participantes. Sendo assim, nossa análise de dados seguiu o seguinte roteiro:

a) Coleta de dados no que se refere às crenças de alunos brasileiros (de japonês como LE) em relação à habilidade de fala na língua japonesa, por meio dos instrumentos de pesquisa anteriormente mencionados;

b) Identificação das crenças;

c) Descrição das crenças;

d) Triangulação dos dados coletados;

e) Análise e interpretação das origens das crenças, baseadas em experiências anteriores de aprendizagem;

f) Análise e interpretação das relações entre as crenças e as EA utilizadas pelos alunos brasileiros de japonês como LE.

Ressaltamos que no presente trabalho não foram adotadas regras de transcrição oficiais, mas procuramos transcrever as falas fielmente.

\section{RESULTADOS}

\subsection{As expectativas, a motivação e as estratégias de aprendizagem}

Os resultados mostraram que os participantes, por não se considerarem hábeis no uso da sua habilidade de fala, sentiam-se inseguros e frustrados durante uma comunicação em japonês. As frustrações seriam decorrentes da timidez, por parte dos aprendizes, e da dificuldade de formular frases completas e passíveis de compreensão durante uma comunicação oral na língua-alvo.

A motivação e expectativa de sucesso dos alunos em relação ao uso oral da língua-alvo também estão relacionadas com essa sensação de frustação. Nina 
e Pedro almejava por uma boa fluência comunicativa na língua-alvo com intuito de conseguirem expressar suas ideias e sentimentos utilizando somente o japonês. Para Oxford e Shearin (1994), "a motivação é considerada por muitos como fator decisivo no sucesso e desenvolvimento de uma segunda língua ou língua estrangeira" (op. cit., p. 12) ${ }^{27}$. As autoras afirmam que a motivação determina o envolvimento pessoal com o estudo da língua-alvo e com as escolhas das estratégias de aprendizado. Segundo Tanaka e Ellis (2003) "as crenças de alunos, juntamente com fatores como atitude e motivação, são consideradas elementos-chave que contribuem para as diferenças individuais na aprendizagem de L2 ${ }^{28}{ }^{29}$ (op. cit., p. 63). Portanto, o fato de ambos os participantes não conseguirem se expressar utilizando a língua-alvo reforça essa sensação de fracasso e não desenvolvimento da parte oral do japonês.

As escolhas das estratégias de aprendizagem pelos alunos também estão diretamente ligadas às motivações e expectativas de Nina e Pedro. Ambos afirmaram que suas motivações ao entrarem no curso superior de Letras-Japonês estavam relacionadas com os seus interesses pessoais por aspectos da cultura japonesa, como animê (desenho japonês), mangá (quadrinhos japonês) e literatura. Portanto, por suas motivações e expectativas também estarem ligadas ao apreço pela cultura japonesa, ambos os participantes declararam que assistiam a filmes, desenhos e novelas em japonês como ferramentas de estudo do japonês. Nina e Pedro também usavam exercícios orais de diálogos como ferramentas de estudo deixando clara a direta relação entre estratégias de aprendizagem, exceptiva e motivação.

As crenças que Nina e Pedro possuem a respeito de sua habilidade de fala também possuem uma relação com as expectativas e frustações dos alunos. Kalaja (2003) afirma que "um conjunto de crenças sobre SLA (aquisição de L2) tem uma ligação com as expectativas de sucesso, onde eles esperam ter sucesso ou falhar nos seus esforços para aprender uma segunda língua ou língua estrangeira" (op. cit., p. 87) ${ }^{30}$ (palavras nossas dentro de parênteses).

27 Tradução nossa. No original: "motivation is considered by many to be one of the main determining factor in success in developing a second or foreign language".

28 Ellis e Tanaka (2003) não fazem distinção entre os termos LE e L2, sendo ambos usados de maneira intercambiável.

29 Tradução nossa. No original: "Learners beliefs, along with factor such as language aptitude and motivation, are considered key elements contributing to individual learner differences in second language (L2) learning".

30 Tradução nossa. No original: "One set of beliefs about SLA has to do with expectations of success, that is, whether a student expects himself to succeed, or fail, I his efforts to learn a second or foreign language". 


\subsection{As crenças}

Pajares (1992) afirma que para "propósitos de investigação, as crenças sejam inferidas" ${ }^{31}$ (op. cit., p. 315). Portanto, a partir dos dados obtidos na análise qualitativa e triangulação de dados, foram elucidadas sete crenças que os participantes têm a respeito de sua habilidade de fala em língua japonesa, descriminadas a seguir:

a) Crença de que a parte oral (uso da HF) da língua japonesa é difícil;

b) Crença de que para comunicar-se em japonês é necessário o conhecimento da gramática e do vocabulário;

c) Crença de que para falar japonês é necessário saber sobre a cultura japonesa;

d) Crença de que para falar japonês é necessário ter uma boa pronúncia;

e) Crença de que as aulas devem ser ministradas somente na língua-alvo;

f) Crença de que é importante praticar a parte oral do japonês com nativos;

g) Crença de que exercícios de diálogos orais são fundamentais para o desenvolvimento da HF.

As crenças mais recorrentes das falas e ações dos participantes em sala de aula referem-se às crenças das letras "a", "b", "d". Este fator nos revela que os alunos, participantes da pesquisa, estão mais preocupados com a forma da língua, ou seja, com o uso correto da gramática e vocabulário, bem com o desenvolvimento de uma boa pronúncia do que o ato de comunicação, ou seja, transmissão de uma mensagem, ideia ou pensamento.

As crenças "c", "e", "f" e "g" estão relacionadas com a motivação dos alunos ao aprenderem a língua japonesa. Ressaltamos que o contexto também ajuda no fortalecimento destas crenças, pois na universidade pública do Distrito Federal, a presença de alunos japoneses de intercâmbio no convívio diário com os alunos do curso de japonês era frequente. Portanto, esses alunos possuem contato direto com nativos falantes de japonês e podem praticar a língua tanto no contexto formal de sala de aula quanto no informal.

Ellis (2008), no seu trabalho de revisão de três estudos sobre crenças, afirma que "as crenças influenciam tanto no processo de aprendizagem quanto no seu resultado" (op. cit., p. 7) 32 . No presente estudo também concluímos que as crenças podem estar dificultando o processo de desenvolvimento da HF dos participantes

31 Tradução nossa. No original: "for purposes of investigation, beliefs must be inferred".

32 Tradução nossa. No original: "beliefs influence, both the process and product of learning". 
na língua-alvo, uma vez que eles estão mais preocupados em produzir uma frase gramaticalmente correta do que no ato de comunicação.

\subsection{A origem das crenças}

Conforme mencionado anteriormente, as crenças "nascem das nossas experiências e problemas" (BARCELOS, 2004, p. 132). Dentro desta perspectiva investigamos a origem das quatro principais crenças que os participantes desta pesquisa possuem a respeito de sua HF através de suas experiências anteriores de aprendizagem. As origens das outras crenças não foram investigadas devido ao curto período destinado para coleta de dados e elaboração do presente estudo. As origens das crenças investigadas foram:

a) Crença de que para comunicar-se em japonês é necessário o conhecimento da gramática e do vocabulário

Origem: Experiência de aprendizagem da língua materna da participante Nina (JEO1). Segundo Nina, ela ingressou na escola regular na primeira série e na época não sabia escrever e falar conforme a língua padrão da sua língua materna, o português, e desde então aparenta ter dificuldade na expressão oral de qualquer língua.

[1] "Não sei, acho que é um problema meu mesmo. Sempre tive mais facilidade em escutar e escrever. Falar eu sempre tive dificuldade, até no português. Porque desde pequena eu falava tudo errado (risos). Eu acho que os meus pais achavam bonitinho a filha falando errado, aí acabaram me ensinando a falar errado também". (Nina, JEO1, E1)

b) Crença de que as aulas de japonês devem ser ministradas somente na língua-alvo

Origem: Experiência de aprendizagem do espanhol da participante Nina (JEO1) e a experiência do primeiro contato com a língua japonesa. Nina afirma que suas aulas de língua espanhola sempre foram ministradas utilizando o castelhano, fator que pode ter contribuído para o desenvolvimento da sua HF.

[2] "No começo da aprendizagem da parte oral foi difícil, pois eu não sabia nem o básico do espanhol. Mas como meu professor falava em espanhol durante todas as aulas e após aprender algumas palavras e estruturas, aos poucos se tornou mais fácil a assimilação da parte oral e com o passar do tempo foi melhorando". (Nina, JEO1, Q1) 
O primeiro contato com a língua japonesa no contexto universitário também pode ter contribuído para a formação da presente crença. Nina afirmou que durante o seu primeiro semestre, apesar de não possuir nenhum conhecimento prévio da língua-alvo, ela conseguia compreender comandos e frases em japonês que a professora utilizava em sala de aula.

\section{c) Crença de que para comunicar-se em japonês é necessário ter uma boa pronúncia}

Origem: Experiência de aprendizagem da língua inglesa pelo participante Pedro (JEO2). Segundo ele, o aprendizado do inglês ocorreu de maneira autodidata com o auxílio de dicionários.

[3] "Eu aprendi com dicionário e lendo (risos). Por conta própria. Eu nunca cheguei a estudar. Bem (pausa), estudei na escola porque era obrigatório. Eu mudei de colégio na época e o colégio que entrei tinha inglês desde a primeira série, e eu entrei na quinta. Eu não entendia absolutamente nada do que tava acontecendo. Acabou que por conta própria, eu pegava um texto que tinha que ler em inglês, pegava o dicionário e lia a palavra por palavra (risos)". (Pedro, JEO2, E1) (palavras entre parênteses nossas).

\section{d) Crença de que exercícios de diálogos orais são fundamentais para o desenvolvimento da HF}

Origem: A origem desta crença também está relacionada com a experiência anterior de aprendizagem de Pedro (JEO2) da língua inglesa, onde a expressão oral do inglês foi estudada por meio de diálogos orais. Para ele, falar está ligado à sensação de que algo está certo ou não, apropriado ou não.

[4] Tem muita coisa que eu aprendi do inglês porque eu sei que tá certo. Porque soa certo. Eu escutei nas coisas, então soa certo quando eu escuto e se eu falar de outra maneira soa errado. (Pedro, JEO2, E1)

\subsection{As crenças e as estratégias de aprendizagem}

Como foi discutido anteriormente, "as crenças de aprendizes sobre aprendizagem de línguas podem influenciar suas estratégias de aprendizagem" (HORWITZ, 1987, p. 120). Yang (1999) também afirmou que "é possível que as crenças dos aprendizes guiem o uso de suas estratégias de aprendizado e que o uso das estratégias de aprendizado dos alunos molde suas crenças sobre aprendizagem de 
línguas" ${ }^{33}$ (op. cit., p. 531). Neste sentido, identificamos as possíveis influências que as crenças exercem sobre as EA e as influências destas nas suas crenças. Vale lembrar que a noção EA é a mesma adotada por Oxford (1990) que afirma que "estratégias de aprendizagem são passos dados pelos alunos para aprimorar seus próprios aprendizados" ${ }^{\prime 34}$ (op. cit., p. 1). Neste sentido, as principais estratégias de aprendizagem para melhorar a HF utilizadas pelos participantes foram: exercícios de diálogos, interação com nativos, filmes, animê (desenho japonês) e novelas em japonesas.

Observamos que algumas das estratégias de aprendizagem desses aprendizes são influenciadas e influenciam nas concepções de suas crenças sobre sua $\mathrm{HF}$ em língua japonesa. Conforme apresentamos anteriormente os participantes da presente pesquisa apresentam crenças que diálogos orais são essenciais para o desenvolvimento da sua HF. Neste sentido, identificamos que a crença de que exercícios de diálogos orais e de que é necessário ter uma boa pronúncia em japonês, influenciam na escolha de exercícios orais como estratégias de estudo do porte oral do japonês.

Outra estratégia utilizada pelos participantes é a de conversar com os falantes nativos com o intuito de praticar a parte oral. $\mathrm{O}$ fato dos participantes da pesquisa possuírem contato direto com falantes nativos da língua-alvo pode ter influenciado na concepção da crença de que é importante praticar a parte oral com nativos com o propósito de desenvolver a HF em japonês. A escolha de filmes, desenhos e novelas em japonês como ferramentas de estudo da parte oral do japonês também possui uma relação direta com as crenças de que para falar japonês é necessário saber sobre a cultura japonesa e ter uma boa pronúncia. Ambos os participantes afirmaram que assistindo a filmes, novelas e desenho em japonês, eles conseguiam obter informações sobre a cultura japonesa e em consequência uma melhor compreensão do uso real da língua. Nina e Pedro afirmaram sempre tentavam "imitar" as frases dos personagens com o intuito de aprimorar a pronúncia no japonês.

\subsection{Crenças, ações e o contexto}

Vale lembrar que as crenças são "contextuais e baseadas nas nossas experiências" (BARCELOS, 2003a, p. 173). Pajares (1992) afirma que "as crenças influenciam as percepções, que influenciam o comportamento" (op. cit., p. 317).

33 Tradução nossa. No original: “ It is possible that learners' beliefs led to their use of learning strategies, or that learners' use of learning strategies shape their beliefs about language learning".

34 Tradução nossa. No original: "Learning strategies are steps taken by students to enhance their own learning". 
Percebemos, por meio das observações de aulas e notas de campo, que os alunos sentiam-se muito inseguros quando se comunicavam dentro da sala de aula. Nina e Pedro formulavam suas sentenças orais de maneira lenta e pausada. Na maioria das aulas, ambos os participantes interagiam comunicativamente com outros colegas e com o professor somente quando perguntas eram dirigidas diretamente para eles. Notamos que o medo de "errar" era frequente durante a formulação das sentenças. A participante Nina, JEO1, criava enunciados simples e com poucos erros gramaticais. As pausas entre frases eram frequentes. O participante Pedro, JEO2, criava enunciados utilizando estruturas mais complexas, mas com grandes pausas antes da finalização do seu ato de fala.

Podemos notar que o presente medo de errar está relacionado com a crença de que para se comunicar em japonês é necessário o domínio do vocabulário e da gramática da língua-alvo. Esta crença por sua vez parece influenciar nas ações dos aprendizes. Em outras palavras, a crença de Nina de que para se comunicar é necessário o domínio da gramática e do vocabulário influencia em suas ações em sala de aula resultando em poucas interações comunicativas. O contexto também contribui para o fortalecimento desta crença. Segundo a participante Nina (JEO1), ela espelha-se nos colegas que possuem certa dificuldade de se expressarem em japonês e sente-se receosa em cometer os mesmos erros. Portanto, devido a esse "medo" e de sua crença em relação ao domínio da língua-alvo, Nina apresenta pouca interação comunicativa no ambiente da sala de aula e o ambiente no qual ela está inserida contribui para o fortalecimento dessa sensação negativa.

Pedro também se mostrou inseguro durante os diálogos dentro do contexto da sala de aula, todavia suas interações comunicativas foram mais frequentes se comparadas com as de Nina. Todavia, os alunos mais comunicativos na turma de JEO1 sempre lideravam as discussões em sala de aula e Pedro falava somente quando uma pergunta era dirigida a ele ou quando o assunto era diretamente ligado aos seus interesses pessoais. Segundo Pedro, formar uma frase gramaticalmente correta e expressar seus sentimentos em japonês ao mesmo tempo é difícil, pois ele afirma precisar pensar bastante antes de falar.

Outro fator relacionado ao contexto seria as afirmações e atitudes do professor em sala de aula. Durante uma aula de JEO1, ministrada em 08 de julho de 2010, o professor da disciplina mencionou para uma aluna com dificuldades de se expressar oralmente na língua-alvo que, sem o domínio da gramática não é possível comunicar-se em japonês. No seu estudo, Barcelos (2003a) mostrou que as crenças de professores exercem influência nas crenças dos alunos e que as crenças dos alunos, por sua vez, também contribuem para ressignificação das crenças dos professores. Na presente pesquisa não investigamos a influência das crenças dos professores no processo de aprendizagem de línguas. Todavia, compreendemos que os atos e afirmações dos professores em sala de aula fazem parte 
do contexto, e este exerce uma influência direta na criação e ressignificações das crenças dos alunos. Neste caso, a fala do professor de JEO1 pode ter contribuído para o fortalecimento da crença de Nina de que para se comunicar em japonês é necessário o domínio da gramática e do vocabulário.

\section{LIMITAÇOES DA PESQUISA}

Uma limitação da pesquisa foi o número limitado de participantes da pesquisa. Devido à limitação de tempo e à natureza da pesquisa, um estudo de caso, optamos por delimitar o número de participantes a somente dois. Outra limitação refere-se somente às elucidações das relações entre crenças, ações e EA. Todavia, acreditamos que essas elucidações confiram a existência dessas relações e suas influências no processo de desenvolvimento da HF dos participantes na língua japonesa.

\section{CONSIDERAÇOES FINAIS}

O estudo das crenças e os papeis que elas exercem no processo de aprendizagem é um importante tópico de investigação na literatura de aquisição de segunda língua (WOODS, 2003; BARCELOS, 2003b, 2006). No presente trabalho realizamos uma investigação inicial das influências das crenças de Pedro e Nina em relação ao uso e desenvolvimento da sua HF em japonês, bem como a influência desta sobre suas crenças no contexto da sala de aula. Vale lembrar que as crenças são contextuais, sociais e com origem nas experiências anteriores de aprendizagem dos aprendizes (BARCELOS, 2001, 2006, 2007). Portanto, ao elucidarmos as crenças de Nina e Pedro investigamos as suas origens baseadas nas experiências anteriores de aprendizagem dos aprendizes na língua materna, inglês, espanhol e japonês.

Entendemos que as crenças exercerem influência sobre as ações e a escolha das EA pelos aprendizes (cf. ABRAHAM; VANN, 1987; BARCELOS, 2000, 2001, 2003a, 2006; CONCEIÇÃO, 2004; HORWITZ, 1987, 1999; HOSENFELD, 2003; KRAMSCH, 2003; PAJARES, 1992; TANAKA; ELLIS, 2003; WENDEN, 1987; WOODS, 2003; YANG, 1999). Sendo assim, por meio da presente pesquisa concluímos que as crenças de Nina e Pedro exercem influência nas suas ações em sala de aula, bem como nas escolhas de suas estratégias de aprendizagem da parte oral do japonês. Ambos por sentirem um constante medo de errar limitavam seus atos de fala em sala de aula, pois acreditam que para se comunicar em japonês é necessário o domínio da língua e possuir uma boa pronúncia. Vale lembrar que Kalaja (2003) afirma que as crenças possuem uma ligação direta com as excep- 
tivas de sucesso de aprendizes durante a aprendizagem de uma segunda língua ou língua estrangeira. Em outras palavras, as crenças, assim como outros fatores, como motivação e expectativas, exercem um papel importante no processo de aprendizagem de línguas (TANAKA; ELLIS, 2003).

A crença de que é importante praticar a parte oral do japonês com nativos e por meio de exercícios de diálogo está diretamente relacionada com o contexto e as experiências anteriores de aprendizagem de línguas de Pedro e Nina. Como mencionado anteriormente, o fato dos participantes por possuírem contato direto com alunos japoneses de intercâmbio japoneses pode ter contribuído para o fortalecimento dessa crença. A crença de que as aulas devem ser ministradas na língua-alvo também possui uma forte ligação com o contexto, expectativas e experiências de aprendizagem anteriores dos alunos. Ambos os participantes afirmaram que se as aulas fossem ministradas desde o início na língua-alvo, eles, provavelmente, sentir-se-iam mais seguros e competentes no uso de sua HF.

Concluímos que as crenças de Nina e Pedro influenciam no seu processo de desenvolvimento da HF em japonês, deixando clara a necessidade de que as pesquisas em aprendizagem de LE são de suma importância e merecem uma atenção continuada. Sabemos que a nossa pesquisa não conseguiu englobar todas as relações das crenças destes aprendizes com o contexto, suas ações e as EA utilizadas e que necessita de futuras investigações. Outro fator que merece atenção continuada é a relação e influência entre as crenças de alunos e professores. Apesar da presente pesquisa não ter analisado a influência direta entre as crenças de alunos e professores, observamos que as crenças, bem como atitudes e falas dos professores contribuem para o fortalecimento e ressignificação das crenças dos alunos. Neste sentido, propomos que a investigação desses fatores continue com o intuito de aprofundar ainda mais o conhecimento gerado na presente pesquisa e para o melhoramento do processo de ensino e aprendizagem de língua estrangeira.

\section{REFERÊNCIAS BIBLIOGRÁFICAS}

ABRAHAM, R. G., VANN, R. J. Strategies of two language learners: a case study. In: WENDEN, A.; RUBIN, J. (Orgs.). Learner strategies in language learning. London: Prentice Hall, 1987, p. 85-102.

BARCELOS, A. M. F. A cultura de aprender línguas estrangeiras (inglês) de alunos formandos de letras. 1995. 220f. Dissertação (Mestrado em Linguística Aplicada) Universidade estadual de campinas, Unicamop, 1995.

Understanding teacher's and student's language learning beliefs in experience: A Dewey Approach. 2000. 357 f. Tese de Doutorado. College of Education, The University of Alabama, Tuscaloosa, 2000. 
. Metodologia de Pesquisa das Crenças sobre Aprendizagem de Línguas: Estado da Arte. Revista Brasileira de Linguística Aplicada, v. 1, n. 1, p. 72-92, 2001.

. Teachers' and students' beliefs within a Deweyan framework: conflict and influence. In: KALAJA, Paula; BARCELOS, Ana Maria Ferreira (Orgs.). Beliefs about SLA: New Research Approaches. Dordrecht: Kluwer, 2003a, p. 171-199.

Researching beliefs about SLA: A critical review. In: KALAJA, Paula; BARCELOS, Ana Maria Ferreira (Orgs.). Beliefs about SLA: New Research Approaches. Dordrecht: Kluwer, 2003b, p.7-33.

Crenças sobre aprendizagem de línguas, Linguística Aplicada e ensino de línguas. Linguagem \& Ensino, v. 7, n. 1, p. 123-156, 2004.

Narrativas, crenças e experiências de aprender inglês. Linguagem \& Ensino, v. 9, n. 2, p. 145-175, 2006.

Crenças sobre ensino e aprendizagem de línguas: Reflexões de uma década de pesquisa no Brasil. In: ALVAREZ, M. L. O.; SILVA, K. A. (Orgs.). Linguística aplicada: múltiplos olhares. Brasília, DF: UnB; Campinas, SP: Pontes Editores, 2007, p. 20-27.

CONCEIÇÃO, M. P. Vocabulário e consulta ao dicionário: analisando as relações entre experiências, crenças e ações na aprendizagem de LE. Belo Horizonte - MG, 2004, 287 f. Tese (Doutorado em Linguística Aplicada) - Faculdade de Letras, Universidade de Minas Gerais, BH, 2004.

CRESWELL, J. W. Research Design: Qualitative, quantitative and Mixed Methods Approach. 3. ed. Thousand Oaks, California: SAGE, 2009.

DEAN, H. H.; BRYSON, K. D. Effective Communication. 2. ed., Englewood Cliffs, N. J.: Printice-Hall, 1961.

DEZIN, N. K.; LINCOLN, Y. S. Introdução: a disciplina e a prática da pesquisa qualitativa. In: DEZIN, N. K.; LINCOLN, Y. S. (Orgs.). O planejamento da pesquisa qualitativa: teorias e abordagens. Porto Alegre: Artmed, 2006, p. 15-41.

DEWEY, John. How we think. Lexington, MA: D.C. Health, 1933.

ELLIS, R. Learner Beliefs and Language Learning. Asian, EFL Journal, 10 (4), p. 7-25, 2008.

FEIJÓ, Flavia Rocha; MUKAI, Yuki. Crenças de alunos brasileiros (de japonês como LE) em relação à competência comunicativa em língua japonesa: pesquisa piloto. In: Congresso Internacional de Estudos Japoneses no Brasil, 8 / Encontro Nacional de Professores Universitários de Língua, Literatura e Cultura Japonesa, 21., 2010, Brasília. Anais. Brasília: Área de Japonês do Departamento de Línguas Estrangeiras e Tradução, 2012, p. 217-224.

FUNDAÇAO JAPAO. Hanasu koto wo oshieru (Ensinar a falar). v. 6. Hitsuji shobô, 2007.

HOROWITZ, M. W.; BERKOWITZ, A. Listening and reading, speaking and writing: An experimental investigation of differential acquisition and reproduction of memory. Perceptual and Motor Skills, 24, p. 207-215, 1967.

HORWITZ, E. K. Using student beliefs about language learning and teaching in the foreign language methods course. Foreign Language Annals, 18 (4), 1985, p. 333-340. 
Surveying students' beliefs about language learning. In: WENDEN, A.; RUBIN, J. (Orgs.). Learner strategies in language learning. London: Prentice Hall, 1987, p. 110-129.

. The beliefs about language learning of beginning University Foreign Language Students. The Modern Language Journal, 72 (3), p. 283-294, 1988.

HOSENFELD, C. Evidence of emergent beliefs of a second language learner: A diary study. In: KALAJA, P.; BARCELOS, A. M. F. (Orgs.). Beliefs about SLA: New Research Approaches. Dordrecht: Kluwer, 2003, p. 37-54.

JOHSON, Donna M. Approaches to Research in Second Language.1. ed., Longman: Nova York, 1992.

KALAJA, Paula. Student beliefs (or metacognitive knowledge) about SLA reconsidered. International Journal of Applied Linguistics, v. 5, n. 2, p. 191-204, 1995.

. Research on Students' beliefs about SLA within a discursive approach. In: KALAJA, P.; BARCELOS, A. M. F. (Orgs.). Beliefs about SLA: New Research Approaches. Dordrecht: Kluwer, 2003, p. 87-108.

KAWAGUCHI, Y.; YOKOMIZO, S. Seichô suru kyôshi no tame no nihongo kyôiku guide book [Jô] (Manual do ensino de língua japonesa para o crescimento de professores [1 ${ }^{\mathbf{0}}$ volume]). 1. ed. Tóquio: Hitsuji Shobô, 2005.

KONDOH, A.; KOMORI, K. Kenkyûsha, Nihongo kyôiku jiten (Enciclopédia de ensino de japonês pela editora kenkyûsha). Kenksyûsha, 2012.

KRAMSCH, C. Metaphor and the subjective construction of beliefs. In: KALAJA, P.; BARCELOS, A. M. F. (Orgs.). Beliefs about SLA: New Research Approaches. Dordrecht: Kluwer, 2003, p. 109-128.

MOURA, M. L. S. de; FERRERIA, M. C.; PAINE, P. A. Manual de elaboração de projetos de pesquisa. 1. ed. Rio de Janeiro: EdUERJ, 1998.

MUKAI, Y. A interlíngua dos aprendizes brasileiros de língua japonesa como LE, com enfoque no uso das partículas wa e ga. Campinas-SP, 2009, $262 \mathrm{f}$. Tese (Doutorado em Linguística Aplicada) - Instituto de Estudos da Linguagem, Universidade Estadual de Campinas.

. Nihongo kyôshi no tame no biriifu kenkyû: kyôshi no seichô wo mezashite (Estudos de crenças para professores de língua japonesa: visando o desenvolvimento dos professores). Brasilia nihongo fukyû kyôkai kyôkaishi (Revista da Associação de Estudos da Língua Japonesa de Brasília), v. 22, p. 45-54, mar. 2011 a.

. JFL nihongo gakushûsha no biriifu kenkyû: nihongo de "kaku (utsu)" koto ni kanshite no yobi kenkyû (Crenças dos aprendizes de japonês como LE: um estudo preliminar sobre a habilidade de "escrita (digitada)" em japonês. Brasilia nihongo fukyû kyôkai kyôkaishi (Revista da Associação de Estudos da Língua Japonesa de Brasília), v. 23, p. 34-50, set. 2011b.

MUKAI, Y.; CONCEIÇÃO, M. P. Aprendendo língua japonesa: crenças, ações e reflexões de uma aluna brasileira de japonês como língua estrangeira. In: MUKAI, Y.; JOKO, A. T.; 
PEREIRA, F. P. (Orgs.). A Língua Japonesa no Brasil: reflexões e experiências de ensino e aprendizagem. 1. ed. Campinas-SP: Pontes Editores, 2012, p. 111-154.

OXFORD, R. L. Language Learning Strategies: What an every teacher should know. Boston: Heinle; Heinle Publishers, 1990.

OXFORD, R.; SHEARIN, J. Language learning motivation: Expanding the Theoretical Frame. The Modern Language Journal, 78 (1), p. 12-28, 1994.

PAJARES, M. F. Teachers' Beliefs and Educational Research: Cleaning Up a Mess Construct. Review of Education Research, n. 3, p. 307-332, 1992.

PEACOCK, M. Beliefs about language learning and their relationship to proficiency. International Journal of Applied Linguistics, 9 (2), p. 247-265, 1999.

SAKUI, K.; GAIES, S. J. Investigating Japanese Learners' beliefs about language learning. System, 27 (4), p. 473-492, 1999.

. A case study: beliefs and metaphors of a Japanese teacher of English. In: KALAJA, P.; BARCELOS, A. M. F. (Orgs.). Beliefs about SLA: New Research Approaches. Dordrecht: Kluwer, 2003, p. 153-170.

SELIGER, H. W.; SHOHAMY, E. Second language research methods. 1. ed. Oxford: Oxford University Press, 1989.

TANAKA, K.; ELLIS, R. Study-abroad, language proficiency, and learners beliefs about language learning. JALT Journal, 25 (1), p. 63-85, 2003.

TELES, J. A. “É pesquisa é? Ah, não quero não, bem!”: sobre pesquisa acadêmica e sua relação com a prática de professor de línguas. Linguagem \& Ensino, 5 (2), p. 91-116, 2002.

VIEIRAABRAHAO, M. H. Metodologia na investigação das crenças. In: BARCELOS, A. M. F.; ABRAHAO VIEIRA, M. H. (Orgs.). Crenças e Ensino de línguas: Foco no professor, no aluno e na formação de professores. Campinas, SP: Pontes, 2005, p. 216-231.

WEDEN, Anita. How to be a successful language learner: insights and prescriptions from L2 learners. WEDEN, Anita; RUBIN, J. (Orgs.). Learner strategies in language learning. London: Prentice Hall, 1987, p. 103-117.

. An Introduction to Metacognitive Knowledge and Beliefs in Language Learning: beyond the basis. System, v. 27, p. 435-441, 1999.

WOODS, D. The social construction of beliefs in the language classroom. In: KALAJA. P.; BARCELOS, A. M. F. (Orgs.). Beliefs about SLA: New Research Approaches. Dordrecht: Kluwer, p. 201-229, 2003.

YANG, Nae-Dong. The relationship between EFL learners' beliefs and learning strategy use. System, 27 (4), p. 515-536, 1999. 


\section{APÊNDICE A - QUESTIONÁRIO SEMIABERTO (Q1)}

O presente questionário faz parte de uma pesquisa em Linguística Aplicada sobre as Crenças de alunos em relação à Competência Comunicativa em Língua Japonesa.

Informo que todas as informações reproduzidas na monografia serão feitas de forma anônima, ou seja, o nome verdadeiro do participante não será revelado.

Sua contribuição é valiosa para o sucesso da pesquisa.

Turma: Japonês Expressão Oral 1 ( )

Japonês Expressão Oral 2 ( )

\section{Informações Pessoais}

Período de Ingresso na UnB:

Semestre atual:

Sexo: F( ) M( )

Idade:

Cidade:

Endereço:

1. Qual foi a sua motivação em ingressar no curso de Língua e Literatura Japonesa? Justifique a resposta.

2. Quando ingressou no curso de japonês já possuía conhecimento prévio da língua? SIM( ) Onde estudou: Período que estudou:

NÃO ( )

3. (Caso tenha respondido sim a perguntar anterior). Com esse conhecimento você já conseguia se comunicar oralmente em japonês?

SIM ( ) NÃO ( ) Parcialmente ( )

Como era a comunicação? Quais foram suas estratégias de aprendizagem, principalmente da parte oral da língua.

4. Você estuda/estudou outra Língua Estrangeira?

SIM ( ) Qual:

Período:

NÃO ( )

5. Como foi o processo de aprendizagem da PARTE ORAL da língua estudada? Poderia descrever-me brevemente? 
6. Compare a parte oral do idioma japonês com a parte oral da língua estudada anteriormente (Grau de dificuldade, uso, aprendizagem). Se possível, poderia exemplificar?

7. A matéria Expressão Oral ( ) não é uma matéria obrigatória na grade curricular do curso de japonês. Por que resolveu cursá-la?

8. Quais são suas expectativas em relação à sua oralidade e à matéria?

9. Até o momento, quais são suas frustrações em relação à sua oralidade e à matéria?

10. Você se considera comunicativamente competente no idioma japonês? Por quê?

11. Como você se sente durante uma interação comunicativa em japonês? Por quê?

12. Na sua opinião, para se tornar comunicativamente competente no Japonês o que é necessário?

13. Atualmente você está satisfeito com seu desempenho comunicativo em japonês? Como poderia melhorá-la e por quê?

14. Você pratica a parte oral do japonês fora da sala de aula? De que maneira?

15. Quais são suas técnicas/recursos de aprendizagem para o estudo da parte oral do idioma japonês? Justifique.

16. Na sua opinião, quais são as estratégias de aprendizagem NECESSÁRIAS para o desenvolvimento da competência comunicativa em japonês?

ESCREVA UMA METÁFORA SOBRE O QUE SERIA UMA PESSOA COMUNICATIVAMENTE COMPETENTE NO IDIOMA JAPONÊS

Brasília, de de 2010

Agradeço à colaboração.

Pesquisadora: Flávia Rocha Feijó 


\section{APÊNDICE B - QUESTIONÁRIO FECHADO (BALLI ADAPTADO) (Q2)}

Questionário formulado com base no BALLI (HORWITZ, 1987), modificado para presente pesquisa.

Abaixo estão listadas algumas crenças a respeito da competência comunicativa em japonês. Leia cada afirmação e decida se:

(1) Concorda plenamente, (2) concorda, (3) não concorda e nem discorda; (4) discorda; (5) discorda completamente. Não existem respostas certas ou erradas. Estamos simplesmente interessados em sua opinião. LEMBRE-SE:

(1) Concorda plenamente, (2) concorda, (3) não concorda e nem discorda; (4) discorda; (5) discorda completamente.

1. Algumas línguas são mais fáceis de aprender do que outras. ( )

A parte oral do Japonês é: (a) muito difícil ( )

(b) difícil ( )

(c) moderado ( )

(d) fácil ( )

(e) muito fácil ( )

2. É importante falar japonês com uma excelente pronúncia. ( )

3. É necessário saber sobre a cultura japonesa para se falar japonês. ( )

4. Não se deve dizer nada em japonês até dizê-lo corretamente. ( )

5. Para desenvolver a parte oral do japonês é necessário ir ao Japão. ( )

6. É bom praticar as falas com os nativos. ( )

7. Para conseguir falar em japonês é necessário saber muito vocabulário. ( )

8. É importante repetir e praticar a parte oral do japonês muito. ( )

9. Eu sinto tímido ao falar com outros em japonês. ( )

10. Se for permitido aos iniciantes cometerem erros, será dificil para eles falarem mais tarde. ( )

11. Para falar em japonês é necessário saber a gramática. ( )

12. É mais fácil falar em japonês do que entender. ( )

13. É mais fácil ler e escrever em japonês do que falar e entender. ( )

14. Para conseguir se expressar bem no japonês é preciso ter domínio da língua. ( )

15. Para o desenvolvimento da competência comunicativa em japonês é necessário que os professores ministrem as aulas em japonês. ( ) 